\title{
Mechanical design of an electronic control unit using axiomatic principles
}

\author{
Vlad Cazacu*, Cristina Savu, Claudiu Gurita, and Gheorghe Nagit \\ “Gheorghe Asachi” Technical University of Iași, Romania
}

\begin{abstract}
If the engine of the car can be considered as the heart, then the E.C.U's represents the brain of the car. Electronic control units (E.C.U's) are electronic devices which control the way different components of a car (engine, windows, airbags, etc.) react in some situations (overheating, button pressed by a passenger, crash, etc.). Axiomatic design is a set of principles that theorizes the act of conceiving a new project. Based on two axiom this method comes into designers help, giving them the option to reach in a short period of time a fully functional and compliant product without supporting the design of the product on chance, past experiences or "try and fail" principle.
\end{abstract}

\section{Introduction}

In the past years, with the overwhelming products that came to market a lot of enterprises put more and more money in research and development departments so the new products that will came to live will be different and attractive for the clients.

The main problems when designing a new product are the cost and the time needed for developing. Both these problems can be solved by using axiomatic design which creates a complete product lifecycle and simplifies the stages through a product has to pass from conception until recycle.

Considering that in automotive industry electronic component became used more and more, the necessity to apply a successfully design method is obvious.

In this paper we will try to apply the axiomatic design for a mechanical design of an ECU which will control the sunroof of a car and the windows, so basically the main input that this ECU will have is provided by the passengers.

\section{Axiomatic design applied to mechanical design of an ECU}

Axiomatic design is considered a pretty new concept, even if there have been several years since professor Nam Pyo Suh presented it. As its founder states, axiomatic design helps in taking "correct decisions", "shorten lead time " ; "improves the quality of products " , "deal with complex systems", "simplify service and maintenance", "exchanges creativity". The ease of use is given by the fact that axiomatic design is based on matrix relationships, so every information given or assumed is connected in an easy to access and review way. Even

\footnotetext{
* Corresponding author: v.cazacuconstantin@yahoo.com
} 
more, for simplifying the means of conceiving, axiomatic design theorizes the act of conceiving by two axioms: The independence axiom and the information axiom. [1-3]

First axiom imposes the maintenance of the functional requirements independent.

Considering the functional requirements (FR) of a product, design parameters (DP) have to be defined so the product gets from the conception state to physical domain. Every functional requirement detected or imposed can be connected with one or more design parameters. Depending the way functional parameters are connected to design parameters, we can create connection matrixes (between FR and DP) which can be diagonal, triangular (superior or inferior) (see figure 1) or any other kind of matrix.

\begin{tabular}{|cccc|}
\hline$A 1$ & 0 & 0 \\
& 0 & $A 2$ & 0 \\
0 & 0 & $A 3$ \\
Diagonal matrix - \\
uncoupled design
\end{tabular}

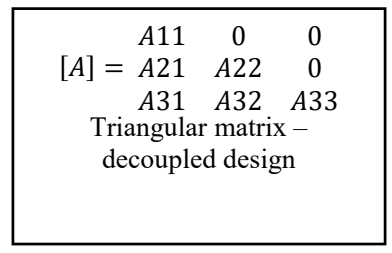

Fig. 1. Axiomatic design resulting matrix types- A1, A2, A3, A11...A33 elements of the resulting matrix.

Each matrix type defines a type of design as it follows: the diagonal matrix defines an ideal design named uncoupled design, triangular matrixes define a decoupled design and for any other types of matrix the resulting design is considered to be a coupled design [4]

In order to create a proper design, it is needed that the resulting design to correspond to first axiom and also it is needed that the matrix $\mathrm{A}$ to be at least a triangular matrix if not a diagonal matrix.

For creating a robust design, it is needed that each functional requirement starting with the intention of design which is considered the zero-hierarchy level to be decomposed into lower and lower functional requirements by respecting the hierarchy and also a zig-zag principle presented in the figure below. [5- 7]

Functional requirements

Physical domain

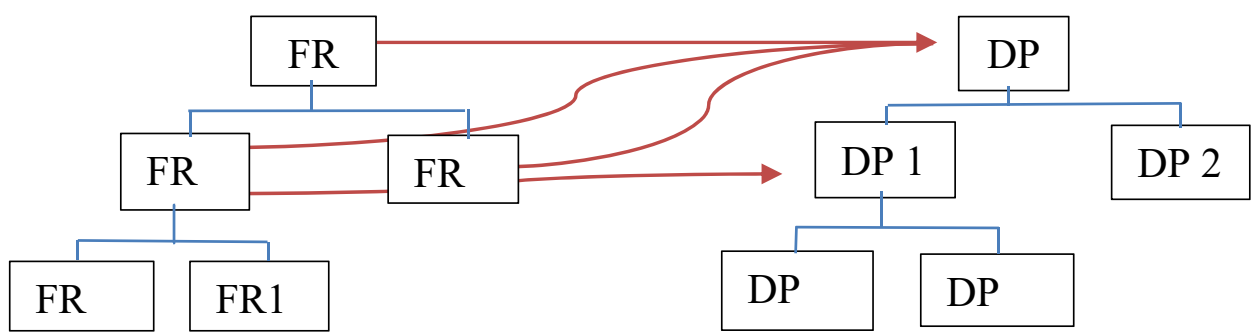

Fig. 2. Functional requirements and conception parameters dependence decomposition.

After the decomposition took place and several designs of the product have been established applying the second axiom will lead to the final design that will be chosen.

Second axiom is used for determining the optimal solution from the multiple solution that have been determined after applying the first axiom.

It defines the quantity of the information (I) of a functional requirement as the probability (P) of the functional requirement to be satisfied [6] 


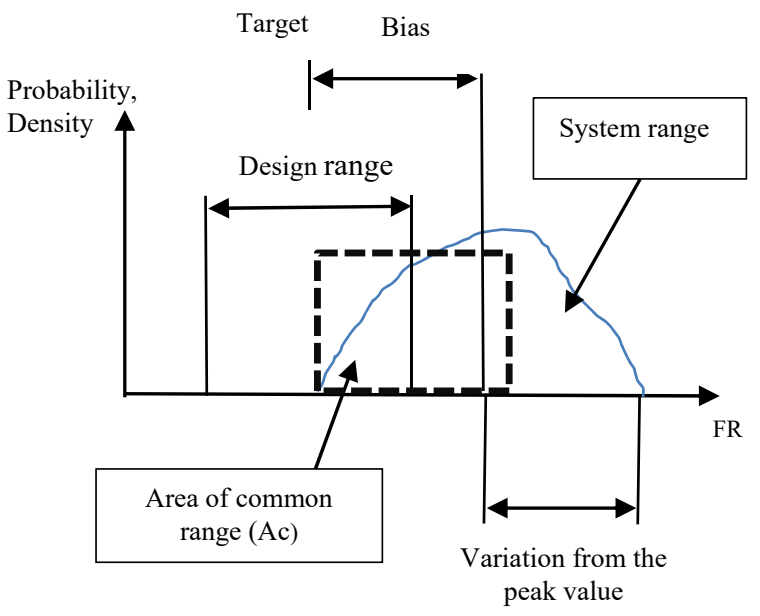

Fig. 3. System range and common range representation of functional requirements in relation with process probability.

$$
I=\log _{2} \frac{1}{P}=-\log _{2} P
$$

For $k$ functional requirements for an uncoupled design $I$ can be expressed as:

$$
I=\sum_{k=1}^{i} \log _{2} \frac{1}{P_{k}}=-\sum_{k=1}^{i} \log _{2} P_{k}
$$

For determining the probability of success it is necessary to determine the System range and the Common range.

System range can be determined as the area under the system range $\left(\mathrm{A}_{\mathrm{sr}}\right)$ graph and the common range is represented by the area under the common range area $\left(\mathrm{A}_{\mathrm{cr}}\right)$ (Fig. 3).

The probability is equal to:

$$
I=\log _{2} \frac{A_{s r}}{A_{c r}}
$$

\section{Practical use}

Practical use will be explained using a mechanical ECU design.

Following the theory given above firstly we have to think the functionality of the product and find the functional requirements. An important contribution in establishing the functional requirements come from the client which states some of the needs that the product will have to accomplish during its production, mounting and functioning.

Client specification:

- Assembly of the parts has to be done with a minimum number of tools [8];

- Maximum dimensions are : $\mathrm{L}=140 \mathrm{~mm} ; \mathrm{l}=100 \mathrm{~mm} ; \mathrm{h}=45 \mathrm{~mm}$;

- Allow the connection with the main computer by two connectors;

- Number of components involved in the assembly have to be less than 10 (the printed circuit board (PCB and its components are considered as 1 item);

- Total weight of the assembly has to be less than $200 \mathrm{~g}$;

- Functionality between $-40{ }^{\circ} \mathrm{C}$ and $110^{\circ} \mathrm{C}$; 
- Mechanical protection IP5KX/IPX1 [9].

Analyzing the client specifications, besides the requirements specified by the client we can establish several more functional requirements which we will centralized in the table below:

- Considering the low weight that the assembly need to have, we will use as material for the housing and cover a plastic material;

- Designing a demountable assembly;

- Material used : plastic, aluminum;

- $\quad$ Assembling features: screws, self-fastening plastic features (snap fit);

- Sealing for mechanical protection: realized by the shape of the assembled parts, introducing supplementary sealing feature (gasket);

- Organizing the PCB inside of the assembly: one or two PCB's;

- Designing a two-piece assembly (cover and housing).

\begin{tabular}{|c|c|c|c|c|c|c|c|c|c|c|}
\hline \multicolumn{11}{|c|}{$\begin{array}{ll}\text { ECU } \\
\end{array}$} \\
\hline \multicolumn{4}{|c|}{ Maximum dimensions } & \multicolumn{2}{|c|}{$\begin{array}{c}\text { Number of } \\
\text { components }\end{array}$} & \multicolumn{5}{|c|}{ Working environment } \\
\hline $\begin{array}{l}\text { Lengt } \\
\mathrm{h}\end{array}$ & $\begin{array}{l}\text { Widt } \\
\mathrm{h}\end{array}$ & $\begin{array}{l}\text { Heigh } \\
\mathrm{t}\end{array}$ & $\begin{array}{l}\text { Weigh } \\
t\end{array}$ & $\begin{array}{l}\text { Con- } \\
\text { nector }\end{array}$ & $\begin{array}{c}\text { Assemble } \\
\mathrm{d}\end{array}$ & \multicolumn{3}{|c|}{$\begin{array}{l}\text { Mechanical } \\
\text { protection }\end{array}$} & \multicolumn{2}{|c|}{$\begin{array}{l}\text { Temperature } \\
\text { range }\left[{ }^{\circ} \mathrm{C}\right]\end{array}$} \\
\hline $\begin{array}{l}140 \\
\mathrm{~mm}\end{array}$ & $\begin{array}{l}100 \\
\mathrm{~mm}\end{array}$ & $\begin{array}{l}40 \\
\mathrm{~mm}\end{array}$ & $200 \mathrm{~g}$ & 2 & $\begin{array}{l}\text { As few as } \\
\text { possible }\end{array}$ & IP51 & KX & $\begin{array}{l}\text { IPX } \\
1\end{array}$ & $-\overline{40}$ & -100 \\
\hline & & & & & $\begin{array}{l}\mathrm{H} \\
\mathrm{o} \\
\mathrm{u} \\
\mathrm{s} \\
\mathrm{i} \\
\mathrm{n} \\
\mathrm{g}\end{array}$ & $\begin{array}{l}\text { C } \\
\text { o } \\
\text { v } \\
\text { e } \\
\text { r }\end{array}$ & $\begin{array}{l}\mathrm{P} \\
\mathrm{C} \\
\mathrm{B}\end{array}$ & $\begin{array}{l}\text { As- } \\
\text { sem- } \\
\text { blin } \\
\mathrm{g} \\
\text { fea- } \\
\text { tures }\end{array}$ & $\begin{array}{l}\text { Dust } \\
\text { pro- } \\
\text { tection }\end{array}$ & $\begin{array}{l}\text { Ver- } \\
\text { tical } \\
\text { water } \\
\text { drips }\end{array}$ \\
\hline
\end{tabular}

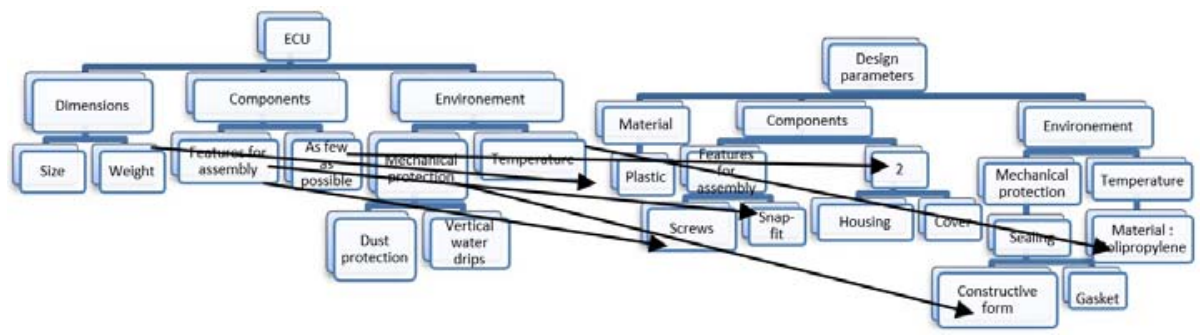

Fig. 4. Functional requirements and design parameters dependences.

After establishing the dependencies between functional requirements and design parameters in the diagram above we created the matrix A (presented in Table 2) bellow which presents the ideal, uncoupled design of the assembly.

As we can see there are many dependencies between single elements related to the ECU and Design Parameters as well as between elements of both. The aim is to obtain a functional constructive form taking into account as many as possible elements and variables which may lead to the desired result. 


\begin{tabular}{|l|c|c|c|c|c|}
\hline \multicolumn{7}{|c|}{ Table 2. The ideal, uncoupled design of the assembly. } \\
\hline & $\begin{array}{l}\text { Use of } \\
\text { plastic }\end{array}$ & $\begin{array}{l}\text { Snap-fit } \\
\text { assembly }\end{array}$ & $\begin{array}{l}\text { Design with 2 } \\
\text { components }\end{array}$ & $\begin{array}{l}\text { Sealing: by } \\
\text { constructive } \\
\text { form }\end{array}$ & $\begin{array}{l}\text { Use of } \\
\text { polypropylene }\end{array}$ \\
\hline Weight & $\mathrm{X}$ & $\mathrm{O}$ & $\mathrm{O}$ & $\mathrm{O}$ & $\mathrm{O}$ \\
\hline $\begin{array}{l}\text { Features for } \\
\text { assembly }\end{array}$ & $\mathrm{O}$ & $\mathrm{X}$ & $\mathrm{O}$ & $\mathrm{O}$ & $\mathrm{O}$ \\
\hline $\begin{array}{l}\text { Use as few } \\
\text { possible } \\
\text { features }\end{array}$ & $\mathrm{O}$ & $\mathrm{O}$ & $\mathrm{X}$ & $\mathrm{O}$ & $\mathrm{O}$ \\
\hline $\begin{array}{l}\text { Mechanical } \\
\text { protection }\end{array}$ & $\mathrm{O}$ & $\mathrm{O}$ & $\mathrm{O}$ & $\mathrm{X}$ & $\mathrm{O}$ \\
\hline $\begin{array}{l}\text { Temperature } \\
\text { range }\end{array}$ & $\mathrm{O}$ & $\mathrm{O}$ & $\mathrm{O}$ & $\mathrm{O}$ & $\mathrm{X}$ \\
\hline
\end{tabular}

From the diagram above (see figure 4) we can observe it results a coupled design because weight and temperature have the same design parameter and also, number of features of assembly is satisfied by two parameter designs: snap-fit assembly and designing only with two components: housing and cover.

From all this we can observe now that our design at this state doesn't respect the first axiom. By reviewing and decomposing the functional requirements we can split the number of components that the client asked for our design into using as few features as possible (thus we chose to have basically two components created by us: housing and cover) and using the snap-fit design for realizing the assembly (this way we remove the need for screws, which will make our overall cost higher).

Also, clearly specifying the material as Polypropylene (PP) we have decomposed the material section and now the resulting matrix drives us to a decoupled design. As we can see from the illustration presented in figure 5 just a few elements from the original setup were taken into account, such as: the snap fit design, the cover, the PCB, the sealing specific to the constructive form, the connectors as well as the housing of the entire assembly itself.

This certifies that this design suits most of the client's requirements.

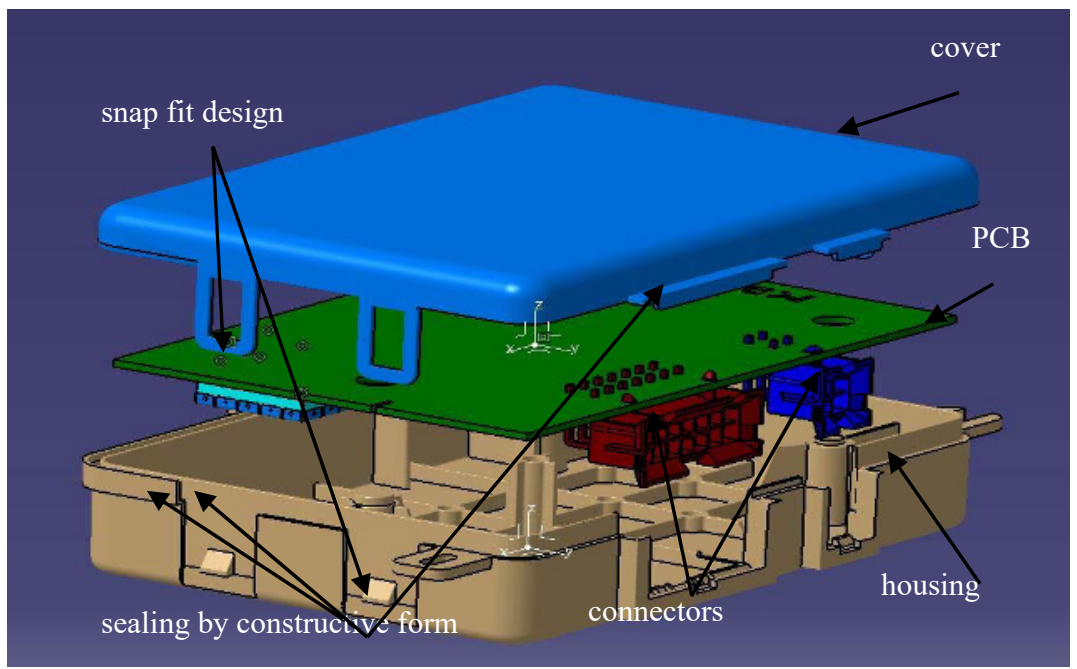

Fig. 5. Final design of the mechanical features of an ECU. 


\section{Conclusion}

Even if we didn't manage to reach the second axiom, we realized a fully functional design (see figure 5) by respecting the first axiom, so our goal of applying the axiomatic design for the mechanical features of an ECU was met. As we hoped we manage to create a compliant design of the ECU which respect all the client requirements and also the requirements imposed by the actual chosen design that derived from the main demands such as the use of plastic materials that involved using the molding injection technology and thus creating draft angles for all the surfaces of the assembly.

Even if we had initially a coupled design, applying decomposition method we were able to reduce the dependences between the functional requirements and the design parameters and we got to the final design which fully respect the first axiom.Described as a facile way of getting to the final goal design, axiomatic design can create difficulties if the designer does not understand the fully functional needs of the product or if he does not initially establish all the possible solutions for the design problem this way, not having enough design parameters to create the design matrix.

In this paper, we demonstrated that axiomatic design is a method of conceiving a product which can drive to a good result by respecting the customer needs, defining the solutions for the requirements, create a solution, analyze it and compare it with the client requirements. Many times the client based specifications are more or less suitable for a proper design in terms of its mechanical properties, cost-performance ratio or even its suitability in the desired market. Nevertheless as it is the case with many other great designs no element or variable should be left aside because it could mean the difference between a great product or just another fail design.

The authors feel that the proposed designs meets all functional parameters as it is already in the production cycles.

\section{References}

1. C. A. Brown, 1st CIRP Conference on Surface Integrity (CSI), Procedia Engineering $1953-59$ (2011);

2. Gollapudi Arun Manohar, International Journal of Research in Engineering and Technology, 430-436 (Apr-2015);

3. Max Fuchs, Michael Eckrich, Olaf Müller, Jan Philipps, Peter Scholz, Advanced designing and validation techniques for electronic control units, 1998 ;

4. Ion Grozav, Quality improvement using axiomatic design, Buletinul AGIR nr. 1-2, (2008);

5. Dym, C. L., Agogino, A. M., Eris, O., Frey, D. D. and Leifer, L. J., Teaching and Learning. Journal of Engineering Education, 103-120 (2005);

6. Q. Cheng, C. Xiao, L. Cai, G. Zhang and P. Gu, Proceedings of the 2012 IEEE 16th International Conference on Computer Supported Cooperative Work in Design (CSCWD), Wuhan, pp. 282-288 (2012);

7. M. Dastagiri and M. M. Prasad, Frontiers in Automobile and Mechanical Engineering, Chennai, pp. 222-228 (2010);

8. System Design and Analysis based on AD and Complexity Theories, https://ocw.mit.edu/courses/mechanical-engineering/2-882-system-design-andanalysis-based-on-ad-and-complexity-theories-spring-2005/lecture-notes/lec202.pdf, retrieved 7.02.2017;

9. ISO $20653: 2013$, Road vehicles - Degrees of protection (IP code) - Protection of electrical equipment against foreign objects, water and access 